\title{
Pairing Nurses and Social Workers in Schools: North Carolina's School-Based Child and Family Support Teams
}

\author{
ELIZABETH J. GIFFORD, PhDa \\ Rebecca Wells, PhD \\ Yu BAl, PhDc \\ TONY O. TROOPd \\ Shari Miller, PhD \\ LesLIE M. BABINSKI, PhD ${ }^{f}$ \\ Received April 20, 2009 \\ Accepted August 24, 2009
}

\begin{abstract}
$\mathrm{W}$ hen children are struggling in school, underlying causes often include physical or behavioral health problems, poverty, abuse, and/or neglect. Children's poor physical health status has been linked to deficits in memory and reading ability. ${ }^{1}$ Children with behavioral problems are much more likely than others to have lower grades, miss school, be suspended or expelled, and drop out. ${ }^{2-4}$
\end{abstract}

Access to needed health and human services is critical to vulnerable children's success in school. Yet, need often does not predict use. Approximately, $7 \%$ of children overall have an unmet need for health care, with the poor, near poor, and uninsured being 3 times more likely than their peers to be underserved. ${ }^{5}$ Only about 1 in 5 children in need of mental health care receive services. ${ }^{6}$

Even available services are often fragmented, making it more difficult for families both to access and utilize them effectively. Increasingly, the federal government, child advocacy groups, and private funders are therefore encouraging any organization that identifies an at-risk child, to convene a team including representatives of all relevant agencies. These teams should include parents as full partners to identify both child and parent needs and to build service plans on strengths as well as needs. ${ }^{7}$ Given their primary role in children's lives, schools are a logical base for such coordination.

The current article describes an innovative effort in North Carolina to help at-risk children thrive academically and remain with their families: the schoolbased Child and Family Support Team Initiative (CFST). The following provides an overview of the program and a profile of the children served in the program's first 2 years.

\section{PROGRAM OVERVIEW}

In 2005, the North Carolina General Assembly established the school-based CFST to facilitate service access for children at risk of school failure or outof-home placement. Beginning in 2005-2006, state funds have supported 1

\footnotetext{
aResearch Scientist, (beth.gifford@duke.edu), Duke University, Box 90545, Durham, NC 27708.

b Associate Professor, (rwells@unc.edu), Gillings School of Global Public Health, Department of Health Policy and Management, University of North Carolina McGavran-Greenberg, CB\# 7411, Chapel Hill, NC 27599-7411.

'Statistician, (yb17@duke.edu), Duke University, Box 90545, Durham, NC 27708.

dProgram Development Coordinator, tony.troop@dhss.nc.gov, School Based Child \& Family Support Team Initiative, NC Division of Public Health, Women's and Children's Health Section, Mail Service Center 1928, Raleigh, NC 27699-1928.

eResearch Psychologist, (shari@rti.org), 3040 Cornwallis Road, P.O. Box 12194, Research Triangle Park, NC 27709-2194.

fResearch Scientist, (leslie.babinski@duke.edu), Duke University, Box 90545, Durham, NC 27708.
}

Address correspondence to: Elizabeth J. Gifford, Research Scientist, (beth.gifford@duke.edu), Duke University, Box 90545, Durham, NC 27708. 
certified school nurse and 1 licensed school social worker in each of 101 schools with a large proportion of high-risk students across the state. These CFST leaders are funded to work full time on CFST. ${ }^{8}$ CFST leaders' primary duty is to coordinate services for at-risk students among education, health, social service, and juvenile justice agencies. They engage with families who have been referred to the program, determine if a CFST is the appropriate resource for the family, schedule and facilitate team meetings with parents, service providers, and community partners, and manage cases, and monitor students' progress. Child and Family Support Team Initiative leaders make home visits to meet the parents who lack transportation, to build trust among families who have disconnected from the school system, and to become familiar with the students' home environment. In most schools, the nurse and social worker fully share responsibility for the majority of cases. In other schools, the nurse and social worker each assume the lead on cases based upon their relative expertise. In either instance, the nurse and social worker support one another throughout this intense process.

A key component of the CFST initiative is the involvement of multiple agencies, including the Departments of Public Instruction (DPI), the Administrative Office of the Courts, the Departments of Juvenile Justice and Delinquency Prevention (DJJDP), Health and Human Services (DHHS), Public Health, Social Services (DSS), and Mental Health, Development Disabilities, and Substance Use (DMH/DD/SAS). Each agency was charged with working together through this program.

Program components of the CFST model include child and family team meetings, service plans, and a Web-based case management system. Each one is described below.

\section{REFERRAL PROCESS}

According to the CFST model, any school faculty or staff member may refer a student to the CFST nurse or social worker for any of the following reasons: academic factors (eg, retained 1 or more years, failed 2 or more classes in a recent semester, sudden drop in grades), excessive absences (eg, excessive tardiness, skips class, leaves early, suspensions), or "inappropriate social interactions" (eg, aggressive or inappropriate behavior, delinquent activities, victim of bullying, withdrawn/change in behavior), and health and human service needs (eg, health and/or mental health concerns, developmental issues, suspected substance use, pregnant/parenting or income related).

Once a CFST leader receives a referral, he or she assesses the student's needs by meeting the parents and gathering information from those who best know the student (including conversations with the student).
Nurses and social workers also periodically visit youths' homes to learn more about family situations and introduce themselves to families. They then schedule a meeting with the student's parent or guardian and other adults who have invested in the child's success (such as ministers and coaches), the student (if sufficiently mature), and representatives of any health and social service organizations believed to be relevant to the child's needs.

\section{CHILD AND FAMILY TEAM MEETINGS}

Meetings are held at a time that the family can attend-often evenings or weekends. A primary objective of the initial meeting is to establish goals for the child that build on child and family strengths and a strategy to achieve those goals, including a plan for all necessary health and social services. Instead of having separate case plans with each agency, the child and his or her family should have a single plan integrating all service providers, a goal summarized as " 1 child, 1 family, 1 plan." The agency relevant to the student's primary unmet need is charged with leading the CFST (eg, school staff lead for academic issues, a behavioral health provider leads for behavioral health problems, or social services lead when the primary unmet need relates to child abuse or neglect). Through subsequent meetings, the group monitors progress and adjusts plans as the child's situation changes.

Research has linked interagency teams to additional receipt of services for children in child welfare as well as sometimes decreased recidivism rates. ${ }^{9}$ When a United Kingdom social services department used a form of child and family teams in 16 schools, parents and students were satisfied with the program and attendance and behavior improved. ${ }^{10}$

\section{CASE MANAGEMENT SYSTEM}

Nurses and social workers enter data on students referred by the CFST program via a Web-based case management system. The information includes student demographics (age, race, ethnicity, gender, grade, special education status), academic, health, and social service needs, team meetings, services plans, follow-up on service plans, and reasons why cases close. These data are used in several ways. First, CFST leaders can track students' needs and ensure receipt of services. Second, aggregate reports allow CFST staff to examine trends in their schools that may inform decisions about where to make additional investments in services. Third, state officials use this information to monitor the program and model fidelity. Finally, the evaluation team at the Center for Child and Family Policy at Duke University is using data from the case management system to assess program impact on academic outcomes by comparing children served 


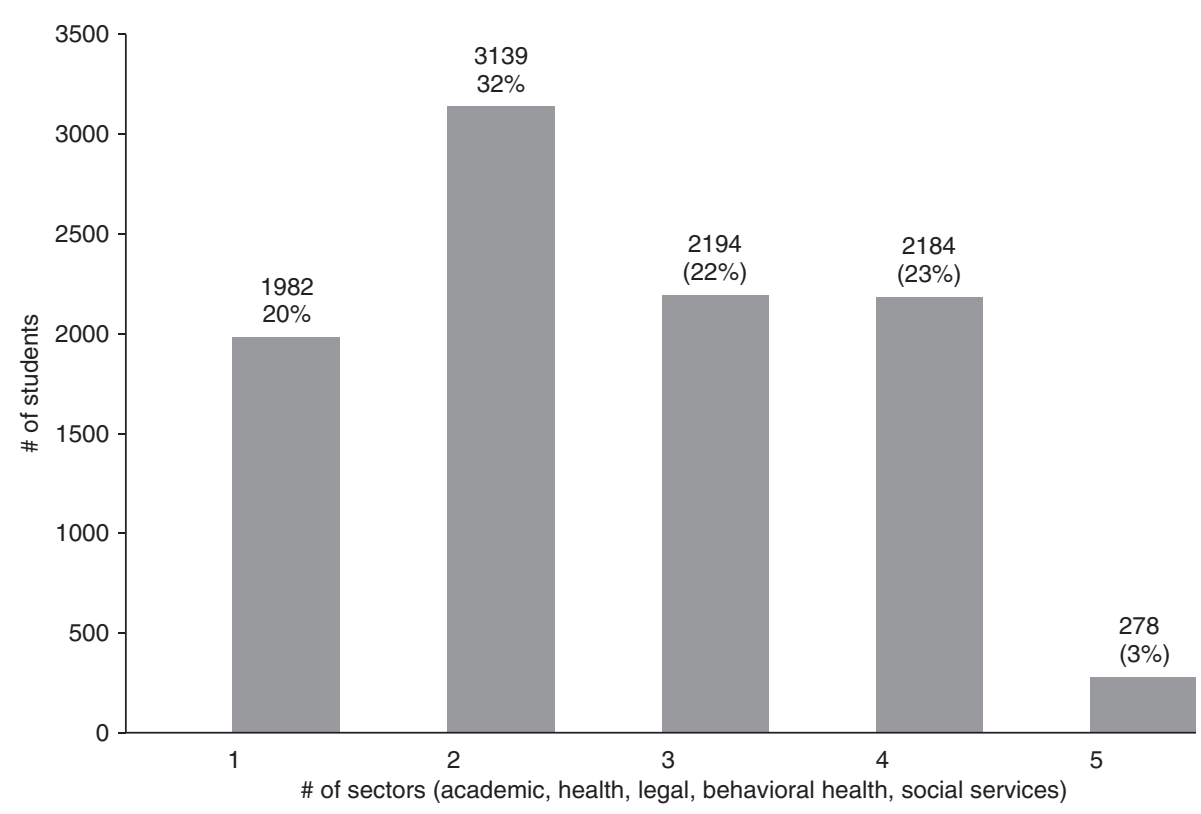

Source: Authors' tabulation of the NC School-Based CFST case management data.

through CFSTs to children in comparable schools who have not been served through CFSTs.

\section{PROFILE OF CHILDREN AND YOUTH SERVED}

During the first 2 years of the program (the 2006-2007 and 2007-2008 academic years), 15,680 students were referred to the program and entered into the case management system, of whom 13,902 $(89 \%)$ had information on needs listed.

About half of the students in the system were in elementary school, $27 \%$ were in middle school, and $24 \%$ were in high school. Boys made up $54 \%$ of those referred. The racial and ethnic composition of the students referred to the CFST program roughly matches the composition of the schools. For example, $53 \%$ of children referred to the CFST program were African-American relative to $53 \%$ of the student body in CFST schools. Similarly, Latinos represented $11 \%$ of the students referred to the CFST program and constitute $12 \%$ of the school body. American Indians represented $3 \%$ of CFST referrals and $3 \%$ of overall school population.

Of the students referred, $73 \%$ had an academic problem, $56 \%$ a health problem, $49 \%$ a mental health, substance use, or developmental need, $65 \%$ a social service need, and $6 \%$ a legal need. As shown in Figure 1, 77\% of students served by CFST had needs that related to more than one sector. One third $(31 \%)$ had 2 needs, $22 \%$ had 3 needs, another $21 \%$ had 4 needs, and $3 \%$ had 5 needs.

\section{IMPLICATIONS FOR SCHOOL LEADERSHIP}

North Carolina's CFST Initiative shows how schools can facilitate access to the health and human services that the vulnerable children need for stability and success. To help students achieve academically, CFST leaders connect students and families to resources such as tutoring, mentoring, counseling, eye glasses, hearing devices, food stamps, housing support, and after-school activities. The nurses and social workers help families initiate behavioral health care for issues such as depression, anxiety, or dealing with family events such as death or illness. They also help families address barriers to receiving services such as lack of transportation. For example, in some school systems the CFST leaders can drive students to services. In other communities, nurses and social workers host meetings in locations easily accessible for families such as churches or community centers.

Of course new models always encounter new challenges. Because some CFST school districts are in very rural counties and nurses could earn higher salaries in other jobs, recruiting qualified nurses has been challenging in a few locations. During the early stages of implementation, a few principals were wary of nurses and social workers leaving school grounds to make home visits and of offering the compensatory time necessary for scheduling evening, early morning, or weekend meetings.

Another challenge has been clarifying and communicating the difference between a CFST nurse and a 
traditional school nurse. In the CFST program, both nurses and social workers address a range of issues affecting academic performance, potentially including family health, social service, and material needs. Unlike most traditional school nurses, CFST nurses serve the population of only 1 school, and address students' needs beyond those pertaining to physical health concerns. If the school had a nurse prior to the CFST initiative, CFST funds could not supplant dollars used for this nurse's salary. Yet, CFST nurses in some schools still routinely receive referrals of children with the types of isolated physical maladies best handled by traditional nurses. Although some nurses have reported significant difficulty communicating the nature of their CFST role to colleagues and parents, many have noted satisfaction from developing deeper and more enduring involvement with families.

At the same time, having a nurse work with a social worker has presented some unexpected opportunities. For instance, when a CFST nurse and social worker visit a home, often the nurse will knock on the door. Experience has shown that families are much less wary of nurses than of social workers, whom they associate with child welfare.

When children's needs are unmet, schools are often the first to identify potential problems. North Carolina's school-based CFST initiative allows schools to create coordinated health care plans so that every student receives the support she/he needs to achieve academic success.

\section{REFERENCES}

1. Kramer RA, Allen L, Gergen PJ. Health and social characteristics and children's cognitive functioning: results from a national cohort. Am J Public Health. 1995;85:312-318.

2. Gall G, Pagano ME, Desmond MS, Perrin JM, Murphy JM. Utility of psychosocial screening at a school-based health center. J Sch Health. 2000;70(7):292-299.

3. Wagner M, Cameto R. The characteristics, experiences and outcomes of youth with emotional disturbances. NLTS2 Data Brief. 2004;3(2). Available at: www.ncset.org/publications/viewdesc. asp?id=1687. Accessed December 8, 2009.

4. Wagner M, Newman L, Cameto R, Garza N, Levine P. After High School: A First Look at the Postschool Experiences of Youth With Disabilities. A report from the National Longitudinal Transition Study-2 (NLTS2). SRI International, Menlo Park, CA, 2005. Available at: www.nlts2.org/reports/2005_04/nlts2 report_2005_04_complete.pdf. Accessed December 8, 2009.

5. Newacheck PW, Hughes DC, Hung Y-Y, Wong S, Stoddard JJ. The unmet health needs of America's children. Pediatrics. 2000;105(4):989-997.

6. Burns BJ, Angold A, Tweed D, et al. Children's mental health service use across service sectors. Health Aff (Millwood). 1995;14(3):147-159.

7. Leaf PJ, Schultz D, Kiser LJ, Pruitt DB. School mental health in systems of care. In: Weist MD, Evans SW, Lever NA, eds. Handbook of School Mental Health: Advancing Practice and Research. New York, NY: Kluwer Academic/Plenum Publisher; 2003: 239-256.

8. Troop T, Tyson CP. School nurses, counselors, and child and family support teams. N C Med J. 2008;69(6):484-486.

9. Baffour TD. Ethnic and gender differences in offending patterns: examining family group conferencing interventions among at-risk adolescents. Child Adolesc Soc Work J. 2006;23(5-6):557.

10. Crow G, Marsh P, Holton E. Summary findings-supporting pupils, schools and families: an evaluation of the Hampshire Family Group Conferences in Education Project. Family and Welfare Findings Series, University of Sheffield; 2004. 